www.jmscr.igmpublication.org

Impact Factor 5.84

Index Copernicus Value: 71.58

ISSN (e)-2347-176x ISSN (p) 2455-0450

crossref DOI: _https://dx.doi.org/10.18535/jmscr/v5i12.68

Journal Of Medical Science And Clinical Research

IGM Publication

An Official Publication of IGM Publication

\title{
Hypofractionated Radiation with concurrent Cisplatin plus Erlotinib in locally advanced squamous cell carcinomas of head and neck: A Feasibility Phase II Study of a Single Institute
}

\author{
Authors \\ Manirathinam Ramalingam ${ }^{1}$, Wani Shahid Bashir ${ }^{2}$, Chandran Nallathambi ${ }^{3}$ \\ Indibor Yengkhom Singh ${ }^{3}$, Devandiran Sivasankaran ${ }^{3}$, Sonia Hage ${ }^{3}$ \\ Adhikarimayum Ambika Devi ${ }^{3}$
}

\begin{abstract}
Aim: To study the feasibility hypofractionated radiation along with standard concurrent Cisplatin plus Erlotinib in Locally advanced squamous cell carcinoma of head and neck (LASCCHN).

Method and Materials: A prospective non-randomized phase II clinical study, undertaken in the Department of Radiotherapy, Regional Institute of Medical Sciences, Imphal, Manipur for a period of 24 months starting from September 2014.Thirty patients were recruited who fulfilled the inclusion criteria. Radiation was delivered using Theratron 780C Cobalt-60 teletherapy unit at a SSD of $80 \mathrm{~cm}$ using shrinking field technique. BED was calculated and spinal sparing done after 16 fractions. Gross tumor received 60 Gy over 24 fractions and 18 fractions was given as a prophylactic dose to low risk nodal areas. Patients also received concurrentcisplatin 30mg/m2 weekly for 5 doses and Tablet Erlotinib $100 \mathrm{mg}$ once a day started 1 week before radiotherapy and upto 4 weeks after completion of radiotherapy. Patients were assessed during radiation weekly and 6 weeks after completing radiotherapy for treatment response and acute radiation toxicity and also after 3 months for late radiation toxicity

Results: The median age of patients was 58 years (range 45-70). A major deviation (three patients) minor deviation (five) in the treatment plan. Two patients out of 7 with oral cavity malignancy, 5 of six with laryngeal carcinoma, 3 of seven with hypo pharyngeal carcinoma and 2 of five in oropharynx carcinoma were attained complete response $(C R)$. Out of 12 patients with the $C R$, five developed locoregional failure $(L R F)$. The median time to LRF was 7 months (range 2-11). One year survival attained by 9 (35\%) patients. Most of them had no hematological toxicity. Grade 3 and 4 mucositis was experienced by 15 $(60 \%)$ and 7 patients (27\%) respectively. Grade 3 dysphagia was seen in 22 patients (85\%) and grade 3 and 4 skin reactions were 9 and 2 patients respectively. More than 75\% experienced grade 2 hoarseness and grade 3 acute salivary gland reaction found in 10 and 15 patients respectively. Most patients had manageable acute toxicities.

Conclusion: Our study emphasizes that its feasible but no superior clinical benefit achieved by using this treatment design, so we recommend not to use except in clinical trials with slight modification

Keywords: Hypofractionated radiation, LASCCHN, Erlotinib, Northeast India.
\end{abstract}

\section{Introduction}

Locally advanced squamous cell carcinoma of head and neck (LASCCHN) managed by combined modality treatment and achieves rather poor results in terms of disease control, organ function preservationor both ${ }^{[1]}$. Loco regional 
failure accounts the predominant recurrence pattern. Radical chemoradiation (CTRT) is another treatment option for LASCCHN, with established benefits in both organ preservation and survival ${ }^{[2]}$. One of the important causes of failure of conventional radiation is accelerated repopulation of tumor clones which usually starts around the $4^{\text {th }}$ week of radiotherapy. To overcome this obstacle and to maximize the therapeutic ratio, altered fractionation scheme was established $^{[3]}$. Another emerging strategy to improve outcomes is to incorporate newer, biologically active, targeted therapies into established chemoradiotherapy programs. More than $90 \%$ of SCCHN tumors overexpress the epidermal growth factor receptor (EGFR $)^{[4]}$ and this has been correlated with poor treatment response, locoregional relapse, and shorter survival in these patients ${ }^{[5]}$. Cetuximaba chimeric antibody against EGFR improves the outcome of patients with recurrent/metastatic disease both in combination with first-line chemotherapy ${ }^{[6]}$ and as monotherapy in platinum refractory tumors ${ }^{[7]}$. Erlotinib is an oral tyrosine kinase inhibitor of EGFR, Preclinical models suggest a significant radiotherapy sensitizing effect ${ }^{[8]}$ and a potential synergism with cisplatin ${ }^{[9]}$. Danish Head and Neck Cancer study group ${ }^{[10]}$ suggesting that an active EGFR signal transduction system is a major indication for ACC RT schedules. Report from CHART trial, where conventional and hyperfractionated/accelerated radiotherapies (HFACC RT) were equally inadequate to locally control tumors with active hypoxia pathways ${ }^{[11]}$. Hypofractionation (Hypo RT) may be necessary in such tumors ${ }^{[12]}$.

\section{Methods and Materials}

A prospective non-randomized phase II clinical study, undertaken in the Department of Radiotherapy, Regional Institute of Medical Sciences (RIMS), Imphal, Manipur for a period of 24 months starting from September 2014 to August 2016 to study the feasibility of hypofractionated radiation with concurrent cisplatin plus erlotinib in LASCCHN. Ethical approval was obtained from Institutional Ethics Committee, RIMS, Imphal before the study. Written informed consent was obtained from the participating individuals.

Patients aged between 30-70 yrs of age with histopathologically confirmed squamous cell carcinoma of the head and neck (AJCC stage III, IVA, IVB) excluding nasopharyngeal carcinoma with Karnofsky performance status (KPS) $\geq 70 \%$ and willing to participate in this study were inclusion criteria for this study.

Radiation was delivered using Theratron $780 \mathrm{C}$ Cobalt-60 teletherapy unit at a SSD of $80 \mathrm{~cm}$ using shrinking field technique. Biological effective dose (BED) was calculated and spinal sparing done after 16 fractions. Gross primary tumor received $60 \mathrm{~Gy} / 2.5 \mathrm{~Gy} /$ fraction over 24 fractions and N1 neck disease received a total dose of upto 52.5 Gy and N2 neck disease received a total dose of upto 57.5 Gy.N3 disease of the neck was given a maximum of $60 \mathrm{~Gy}$. Prophylactic dose of 45 Gy to clinically and radiologically negative but at risk nodal areas were delivered. Cisplatin was administered concurrently at a dose of $30 \mathrm{mg} / \mathrm{m}^{2}$ weekly for a total of 5 dosesand Tab. Erlotinib 100mg once a day started 1 week before radiotherapy and upto 4 weeks after completion of radiotherapy. Patients were assessed during radiation treatment weekly and 6 weeks after completing radiotherapy for treatment response and acute radiation toxicity and also after 3 months for late radiation toxicity. Treatment response, toxicity were assessed using RECIST Criteria and RTOG toxicity Criteria respectively. All patients enrolled were analyzed with intent to treat. Means and percentages were calculated for different variables. Data were analyzed using SPSS to determine the statistical significance of the treatment regime among different variables.

\section{Results and observation}

The median age of patients was 58 years (range 45-70). Out of 30 patients, 21 were male and nine 
were female. Other patient and tumor characteristics are summarized in table.1.

During the course of treatment hospital admission was required for $12(46.2 \%)$ patients. The reasons for the admission were dehydration due to severe mucositis, profuse vomiting and infections (fungal, bacterial) managed symptomatically with nutritional support and antimicrobial agents. Nasogastric feeding tube has been inserted for 18 patients. One patient had grade 2 skin lesion for which Erlotinib was stopped for one week. Twenty patients received chemo as per planned schedule and 6 patients received 4 cycles only due to severe acute radiation reactions and this was considered as the minor deviation in the treatment plan. Two of these 6 patients also had severe skin lesions (acne, erythematous lesion) so Tab. Erlotinib was stopped for two weeks. Radiation was stopped for 7 days in another patient due to grade IV mucositis. These three patients were considered to have a major deviation (three patients) in the treatment plan. Total eight patients had a deviation $(5+3)$ in the treatment plan.

All patients received the intended tumor dose except one, due to unavailability of conformal therapy for the posterior neck nodes. Treatment was completed within 35 days in 11 patients and within 40 days in 12 patients. The median time of delivery for these patients was 37 days (range, 3155 days). Out of 30 patients, Two were excluded in the assessment of the toxicity and four were excluded from response evaluation analysis. Out of this 4 patients, Two were not completed their treatment due to their personnel reasons, one died just 2 days after completing the treatment and one found to have brain metastasis at the fourth week of CTRT.

The median follow-up of all patients was 9.5 months (range 2-18 months). Complete and partial responses were achieved in $12(46.2 \%)$ patients each with an overall response rate of $92 \%$ and two patients were having stable disease. Two patients out of eight with oral cavity malignancy, 5 of six with laryngeal carcinoma, 3 of seven with hypopharyngeal carcinoma and 2 of five in oropharynx carcinoma were attained complete response. Out of 12 patients with the complete response, five patients developed locoregional disease recurrence. Recurrence observed in two cases of hypopharynx and the remaining three were distributed by each other site. The median time to locoregional recurrence was 7 months (range 2-11months). One patient developed recurrence at primary as well as nodal site and the remaining four at nodal site only. Of five patients one patient died of disease recurrence and other patients planned for further salvage treatment. Distant metastasis were seen in one patient as we mentioned before.

Most of them had no hematological toxicity. Grade 2 anaemia occurred in four patients, grade 2 neutropenia was in three patients for which they received blood transfusion and granulocyte colony stimulating factors. Other toxicity profile are summarized in table 3 and 4.

Table 1. Patient and tumor characteristics

\begin{tabular}{|c|c|c|c|}
\hline variables & Sub variables & $\begin{array}{l}\text { Frequency } \\
\quad(n=30)\end{array}$ & $\begin{array}{c}\text { Percentage } \\
(\%)\end{array}$ \\
\hline \multirow[b]{2}{*}{ Sex } & male & 21 & 70 \\
\hline & female & 9 & 30 \\
\hline \multirow{4}{*}{ Site } & Oral cavity & 8 & 26.7 \\
\hline & Oro pharynx & 7 & 23.3 \\
\hline & Larynx & 7 & 23.3 \\
\hline & Hypopharynx & 8 & 26.7 \\
\hline \multirow{11}{*}{ Subsite } & Ant $2 / 3$ tongue & 4 & 13.3 \\
\hline & Floor of mouth & 1 & 3.3 \\
\hline & Buccal mucosa & 1 & 3.3 \\
\hline & Hard palate & 2 & 6.7 \\
\hline & Tonsil & 2 & 6.7 \\
\hline & Post $3^{\text {rd }}$ tongue & 4 & 13.3 \\
\hline & Soft palate & 1 & 3.3 \\
\hline & Supraglottis & 4 & 13.3 \\
\hline & Glottis & 2 & 6.7 \\
\hline & PFS & 7 & 23.3 \\
\hline & PPW & 2 & 6.7 \\
\hline \multirow[b]{3}{*}{ Stage } & III & 7 & 23.3 \\
\hline & IV A & 21 & 70.0 \\
\hline & IV B & 2 & 6.7 \\
\hline \multirow{4}{*}{ Grade } & Well differentiated & 7 & 23.3 \\
\hline & Mod differentiated & 14 & 46.7 \\
\hline & Poor differentiated & 8 & 26.7 \\
\hline & Un differentiated & 1 & 3.3 \\
\hline
\end{tabular}


Table 2 Response rate in patients according to RECIST criteria

\begin{tabular}{|l|c|c|}
\hline Tumour response & $\begin{array}{c}\text { Frequency } \\
(\mathrm{n}=26)\end{array}$ & Percentage (\%) \\
\hline Complete response & 12 & 46.2 \\
\hline Partial response & 12 & 46.2 \\
\hline Stable disease & 2 & 7.7 \\
\hline
\end{tabular}

Abbreviations: RECIST- Response Evaluation Criteria in Solid Tumor

Table 3 Acute radiation toxicity in study population $n=28(\%)$

\begin{tabular}{|c|c|c|c|c|c|}
\hline \multirow{4}{*}{ Mucositis } & Grade & Week 2 & Week 3 & Week 4 & Week 5 \\
\hline & Grade 2 & $3(10.7)$ & $12(42.9)$ & $8(28.6)$ & $7(25.0)$ \\
\hline & Grade 3 & nil & $12(42.9)$ & $13(46.4)$ & $17(60.7)$ \\
\hline & Grade 4 & nil & nil & $7(26.9)$ & $2(6.7)$ \\
\hline \multirow{3}{*}{ Skin reaction } & Grade 2 & nil & $6(21.4)$ & $9(32.1)$ & $7(25.0)$ \\
\hline & Grade 3 & nil & nil & $6(21.4)$ & $11(39.3)$ \\
\hline & Grade 4 & nil & nil & $2(7.1)$ & $1(3.6)$ \\
\hline \multirow{3}{*}{ Dysphagia } & Grade 2 & $3(10.7)$ & $13(46.4)$ & $4(14.3)$ & $7(25.0)$ \\
\hline & Grade 3 & nil & $12(42.9)$ & 24 (85.7) & $20(71.4)$ \\
\hline & Grade 4 & nil & nil & nil & nil \\
\hline \multirow{3}{*}{ Hoarseness } & Grade 2 & nil & $12(42.9)$ & $23(82.1)$ & $18(64.3)$ \\
\hline & Grade 3 & nil & nil & $1(3.6)$ & $4(14.3)$ \\
\hline & Grade 4 & nil & nil & nil & nil \\
\hline \multirow{3}{*}{ Salivary gland } & Grade 2 & nil & $17(60.7)$ & $11(39.3)$ & $11(39.3)$ \\
\hline & Grade 3 & nil & $3(10.7)$ & 15 (53.6) & $14(50.0)$ \\
\hline & Grade 4 & nil & nil & nil & nil \\
\hline
\end{tabular}

Table 4 Late radiation toxicity in study population $\mathrm{n}=28(\%)$

\begin{tabular}{|l|c|c|c|c|}
\hline Toxicities & Grade & $3^{\text {rd }}$ month & $6^{\text {th }}$ month & $9^{\text {th }}$ month \\
\hline \multirow{3}{*}{ Skin reaction } & Grade 1 & $17(60.7)$ & $19(67.9)$ & $11(39.3)$ \\
\cline { 2 - 5 } & Grade 2 & $4(14.3)$ & $5(17.9)$ & $2(7.1)$ \\
\cline { 2 - 5 } & Grade 3 & nil & nil & nil \\
\hline \multirow{3}{*}{$\begin{array}{l}\text { Subcutaneous } \\
\text { fibrosis }\end{array}$} & Grade1 & $13(46.4)$ & $9(32.1)$ & $4(14.3)$ \\
\cline { 2 - 5 } & Grade 2 & $12(42.9)$ & $1(50.0)$ & $9(32.1)$ \\
\cline { 2 - 5 } & Grade 3 & nil & nil & nil \\
\hline \multirow{3}{*}{ Hysphitis } & Grade 1 & $13(46.4)$ & $12(42.9)$ & $4(14.3)$ \\
\cline { 2 - 5 } & Grade 2 & $11(39.3)$ & $10(35.7)$ & $6(21.4)$ \\
\cline { 2 - 5 } & Grade 3 & nil & nil & nil \\
\hline \multirow{3}{*}{ Xoarseness } & Grade 1 & $6(21.4)$ & $6(21.4)$ & $2(7.1)$ \\
\cline { 2 - 5 } & Grade 2 & $19(67.9)$ & $13(46.4)$ & $8(28.6)$ \\
\cline { 2 - 5 } & Grade 3 & $1(3.8)$ & $5(19.2)$ & $3(10.7)$ \\
\hline & Grade 1 & $13(46.4)$ & $16(57.1)$ & $10(35.7)$ \\
\cline { 2 - 5 } & Grade 2 & $13(46.4)$ & $9(32.1)$ & $1(3.6)$ \\
\cline { 2 - 5 } & Grade 3 & nil & nil & nil \\
\hline & Grade 1 & $5(17.9)$ & $7(25.0)$ & $5(17.9)$ \\
\cline { 2 - 5 } & Grade 2 & $20(71.4)$ & $16(57.1)$ & $7(25.0)$ \\
\cline { 2 - 5 } & Grade 3 & $1(3.6)$ & $2(7.1)$ & $1(3.6)$ \\
\hline
\end{tabular}

\section{Discussion}

This is a preliminary phase II study done in north eastern part of India. Prevalence of the head and neck malignancy in this part of the people is high due to their continuous use of tobacco (various form) and their lifestyle. Most of them comes with the advanced stages due to their negligence, unawareness, and poverty. Achieving long-term local control (LC) in LASCCHN remains a challenge. 
In this study, complete response was observed in $12(46.2 \%)$ patients, this report is contrast to previous studies. Michel et $\mathrm{al}^{[13]}$ studied Conformal hypofractionated RT with amifostine combined with cisplatin and cetuximab in patients with LAHNC, there complete response rate was $68.57 \%$. The discrepancy is due to use of conformal hypofractionated RT, the use of amifostine which reduced mucositis that contributed to less interruption in the treatment and some patients underwent nodal dissection. Some Other studies also showed superior response rate compared to our study ${ }^{[14]}$.

Another study by AK chan et al ${ }^{[15]}$ observed that 2 year local control rate of $78.3 \%$ for all patients treated with hypofractionated accelerated radiotherapy with platinum chemotherapy for locally advanced SCCHN. The use of nodal dissection and early stage $(\mathrm{T} 1, \mathrm{~T} 2)$ patients accrual could be reason for the discordance with our study. The preoperative and postoperative neck dissections may also influence the control rates.

Acute radiation reactions were high as expected, it contributed the major and minor deviation in the treatment plan for some patients and increase in overall treat time (OTT).Prolongation of OTT contributed by social factors (strike), patient factors (noncompliance) and mechanical factors (machine break down) also. This could be reason for the low response rate in our study. The (DAHANCA) $6 \& 7$ randomized control trial demonstrated that reducing the overall treatment time by 1 week, while maintaining the same dose and fractionation schedules, improved the 5-year LC by $10 \%^{[16]}$.

In this study, grade 3 and 4 acute toxicities especially mucositis, skin reaction and dysphagia were high which is almost concordance with previous studies $^{[17,18]}$.

Patients suffered from skin toxicities (rash) were less inspite of combining of erlotinib and cisplatin. The use of erlotinib did not compromise the delivery of cisplatin or radiotherapy except in one patient. Again study by Rento et al ${ }^{[19]}$ showed that $68 \%$ of patient had skin rash this might be use of high dose cisplatin in their study.

The incidence of late side effects of RT within a median of 9.5 months of follow-up was within acceptable levels, despite the use of hypofractionation. Longer follow-up is certainly needed to better estimate late adverse events.

All the patients who had loco-regional failure were presented with $\mathrm{N} 3$ node at initial presentation. This denotes that patients with a large nodal burden are probably less likely to be benefited by hypofractionation. This outcome is well-corroborated with MARCH collaborative group meta-analysis ${ }^{[20]}$ which has shown that the effect of altered fractionation was significantly more pronounced on the primary tumor than on the nodal disease. Rishi et al. showed that patient with nodal size greater than $2 \mathrm{~cm} \times 2 \mathrm{~cm}$ had significantly poor disease free survival (DFS) with concomitant boost as compared to conventional chemoradiation $^{[21]}$.

Patients with laryngeal cancer fared better compared to other site in this study. Larynx is the one of the best prognostic site among the head and neck malignancy and it has been confirmed by previous studies. Patients treated with hypofractionated RT and carboplatin concurrently by $\mathrm{AK}$ Chan et $\mathrm{al}^{[22]}$, also reported that 2 year overall survival, disease free survival and local control were superior in oropharynx followed by larynx with minimal difference in between them.

Limitations of our study include a limited followup time and a heterogeneous group of patients with locally advanced HNC. We were unable to show a significant difference in overall survival (OS) and disease free survival (DFS), most probably due to majority of study patients with poor prognostic features, limitation of facility, not able to complete treatment within particular period. The use of neck dissection, conformal therapy and the ability to complete treatment within the prescribed overall treatment time would have contributed better results. 


\section{Conclusion}

Our study emphasizes that, its feasible but no superior clinical benefit achieved by using this treatment design, so we recommend not to use except in clinical trials with slight modification.

\section{References}

1. Foote RL, Ang KK. Head and neck tumors-over view. In: Gunderson, Tepper, editor. Clinical radiation oncology. 3rd ed. New York; Elsevier; 2000. p. 425-6.

2. Wolf TG, Hong WK, Fisher SG, Urba S, Endicott JW, Close L, et al. The department of veterans affairs laryngeal cancer study group. Induction chemotherapy plus radiation compared with surgery plus radiation in patients with advanced laryngeal cancer. N Engl J Med 1991;324(24):1685-90

3. Hall EJ, Garcia Amato J. Time, dose and fractionation in radiotherapy.In: Hall EJ, editors. Radiobiology for the radiologists. 6th ed. Philadelphia: Lippincott Williams and Wilkins; 2006. p. 378-97.

4. Argiris A, Karamouzis MV, Raben D, Ferris RL. Head and neck cancer. Lancet 2008;371(9625):1695-09.

5. Cohen EE. Role of epidermal growth factor receptor pathway targeted therapy in patients with recurrent and/or metastatic squamous cell carcinoma of the head and neck. J ClinOncol 2006;24(17):2659-65.

6. Vermorken JB, Mesia R, Rivera F, Remenar E, Kawecki A, Rottey S, et al. Platinum based chemotherapy plus cetuximab in head and neck cancer. N Engl J Med 2008;359(11):1116-27.

7. Vermorken JB, Trigo J, Hitt R, Koralewski P, Diaz-Rubio E, Rolland F, et al. Open label, uncontrolled, multicenter phase II study to evaluate the efficacy and toxicity of cetuximab as a single agent in patients with recurrent and/or meta- static squamous cell carcinoma of head and neck who failed to respond to platinum-based therapy. J Clin Oncol 2007;25(16):2171-7.

8. Harari PM, Allen GW, Bonner JA. Biology of interactions: Antiepidermal growth factor receptor agents. J ClinOncol 2007;25(26):4057-65.

9. Higgins B, Kolinsky K, Smith M, Beck G, Rashed M, Adames V, et al. Antitumor activity of erlotinib alone or in combination in human non small cell lung cancer tumor xenograft models. Anticancer drugs 2004;15(5):503- 12.

10. Eriksen JG, Steiniche T. Overgaard J for the danish head and neck cancer study group: The role of epidermal growth factor receptor and E-cadherin for the outcome of reduction in the overall treatment time of radiotherapy of supraglottic larynx squamous cell carcinoma. ActaOncol 2005;44(1):50-8.

11. Koukourakis MI, Bentzen SM, Giatromanolaki A, Wilson GD, Daley FM, Saunders MI, et al. Endogenous markers of two separate hypoxia response pathways (hypoxia inducible factor 2 alpha and carbonic anhydrase 9) are associated with radiotherapy failure in head and neck cancer patients recruited in the CHART randomized trial. $\mathrm{J}$ ClinOncol 2006;24(5):727-35.

12. Koukourakis MI, Giatromanolaki A, Danielidis V, Sivridis E. Hypoxia inducible factor (HIF1alpha and HIF2alpha) and carbonic anhydrase 9 (CA9) expression and response of head and neck cancer to hypofractionated and accelerated radiotherapy. Int J RadiatBiol 2008;84(1):47-52.

13. Koukourakis MI, Tsoutsou PG, Karpouzis A, Tsiarkatsi M, Karapantzos I, Daniilidis $\mathrm{V}$, et al. Radiochemotherapy with cetuximab, cisplatin, and amifostine for locally advanced head and neck cancer. A feasibility study. Int $\mathrm{J}$ RadiatOncol 2010;77(1):9-15. 
14. Roy S, Mallik C, Ghorai S, Hazra A, Majumdar A. Hypofractionated versus conventional radiotherapy with or without chemotherapy in head and neck cancer: A comparative study. Clin Cancer Investig $\mathbf{J}$ 2015;4(2):140-6.

15. Chan AK, Sanghera P, Choo BA, McConkey C, Mehanna H, Parmar S, et al. Hypofractionated accelerated radiotherapy with concurrent carboplatin for locally advanced squamous cell carcinoma of the head and neck. J Clin Oncol 2011;23 (1):34-39.

16. Pryor DI, Porceddu SV, Burmeister BH, Guminski A, Thomson DB, Shepherdson $\mathrm{K}$, et al. Enhanced toxicity with concurrent cetuximab and radiotherapy in head and neck cancer. Radiother Oncol 2009;90 (2):166-71.

17. Bonner JA, Harari PM, Giralt J, Cohen RB, Jones CU, Sur RK, et al. Radio therapy plus cetuximab for locoregionally advanced head and neck cancer: 5-year survival data from a phase 3 randomized, and relation between cetuximab induced rash and survival. Lancet Oncol 2010;11(1):21- 8

18. Yu E, Shenouda G, Beaudet MP, Black MJ. Impact of radiation therapy fraction size on local control of early glottic carcinoma. Int $\mathbf{J}$ RadiatOncolBiolPhys 1997;37(3):587-91.

19. Martins R, Parvathaneni U, Sharma AK, Raez LE, Papagikos MA, Yunus F, et al. Cisplatin and radiotherapy with or without erlotinib in locally advanced squamous cell carcinoma of the head and neck. A randomized phase II trial. J ClinOncol 2013;31(11):1415-21.

20. Bourhis J, Overgaard J, Audry H, Ang KK, Saunders M, Bernier $J$, et al. Hyperfractionated or accelerated radiotherapy in head and neck cancer: A metaanalysis. Lancet 2006;368(9538):843-54.
21. Rishi A, Ghoshal S, Verma R, Oinam AS, Patil VM, Mohinder R, et al. Comparison of concomitant boost radiotherapy against concurrent chemoradiation in locally advanced oropharyngeal cancers: A phase III randomised trial. RadiotherOncol 2013;107(3):317-24.

22. Chan AK, Sanghera P, Choo BA, McConkey C, Mehanna H, Parmar S, et al. Hypofractionated accelerated radiotherapy with concurrent carboplatin for locally advanced squamous cell carcinoma of the head and neck. J ClinOncol 2011;23 (1):34-39. 